\title{
Prevalence of Metabolic Syndrome in Japanese-Brazilians According to Specific Definitions for Ethnicity
}

\author{
Natasha P. Xavier, M.S., ${ }^{1}$ Rita C. Chaim, Ph.D., ${ }^{2}$ Suely G.A. Gimeno, Ph.D., ${ }^{3}$ Sandra R.G. Ferreira, M.D., ${ }^{4}$ \\ Amelia T. Hirai, M.D., ${ }^{3}$ Carlos R. Padovani, Ph.D., ${ }^{5}$ Marina P. Okoshi, M.D., ${ }^{1}$ and Katashi Okoshi, M.D. ${ }^{1}$
}

\begin{abstract}
Background: The American Heart Association/National Heart, Lung, and Blood Institute (AHA/NHLBI), revising the National Cholesterol Evaluation Program for Adult Treatment Panel III (NCEP ATP III), and the International Diabetes Federation (IDF) have proposed definitions of metabolic syndrome that take into account waist circumference thresholds according to ethnicity. In this study we estimated the prevalence of metabolic syndrome in a Japanese-Brazilian population using NCEP definitions for Westerners (NCEPwe) and Asians (NCEPas), and IDF for Japanese (IDF).

Methods: A total of 650 Japanese-Brazilians living in a developed Brazilian city and aged 30-88 years were included.

Results: Metabolic syndrome prevalence according to NCEPwe, NCEPas, and IDF was, respectively, $46.5 \%$, $56.5 \%$, and $48.3 \%$. Only $43.5 \%$ of subjects did not have metabolic syndrome by any of the 3 definitions, and $38.3 \%$ fulfilled metabolic syndrome criteria for all 3 definitions. Ten percent of subjects were positive for metabolic syndrome based on NCEPas and IDF, but not for NCEPwe. Because IDF requires abdominal obesity as a criterion, the frequency of subjects without metabolic syndrome according to IDF, but with metabolic syndrome by NCEPwe and NCEPas was $8.2 \%$.

Conclusions: Independent of the metabolic syndrome definition, Japanese-Brazilians present an elevated metabolic syndrome prevalence, which was higher when using NCEP criteria for Asians, followed by the IDF definition for Japanese.
\end{abstract}

\section{Introduction}

$\mathrm{M}$ ETABOLIC SYNDROME ENCOMPASSES SEVERAL COMPOnents that predispose individuals to a higher risk of cardiovascular events, such as coronary artery disease, myocardial infarction, heart failure, and encephalic vascular accident, contributing to increased cardiovascular morbimortality. ${ }^{1}$ Patients with metabolic syndrome are also at increased risk of developing type 2 diabetes mellitus (T2DM). ${ }^{2}$ An essential component involved in the metabolic syndrome pathophysiology appears to be insulin resistance, with consequent hyperinsulinemia resulting mainly from excessive circulating free fatty acids. Obesity, particularly the visceral variety, has been considered a key component for developing insulin resistance. ${ }^{3,4}$
Asians have a greater tendency than Caucasians to deposit adipose tissue as abdominal visceral fat rather than abdominal subcutaneous fat. ${ }^{5,6}$ Probably due to increased intraabdominal fat deposition, Japanese are susceptible to T2DM and cardiovascular disease despite a relatively normal body mass index (BMI). 5, Taking this into account, the International Diabetes Institute (IDI), a center that collaborates with the World Health Organization (WHO), proposed specific values to characterize total and abdominal obesity in Asian populations. Subjects with BMI values between 25.0 and $29.9 \mathrm{~kg} / \mathrm{m}^{2}$ and BMI $\geq 30.0$ $\mathrm{kg} / \mathrm{m}^{2}$ were classified as I and II degree obesity, respectively, and associated with moderate and severe risk for developing co-morbidities. Central obesity was defined as waist circumference $\geq 90 \mathrm{~cm}$ in men and $\geq 80 \mathrm{~cm}$ in women. ${ }^{7}$

\footnotetext{
${ }^{1}$ Department of Internal Medicine, Botucatu Medical School, São Paulo State University, Botucatu, São Paulo, Brazil.

${ }^{2}$ Department of Nutrition, Sacred Heart University, Bauru, São Paulo, Brazil.

${ }^{3}$ Department of Preventive Medicine, Federal University of São Paulo, São Paulo, Brazil.

${ }^{4}$ Department of Nutrition, School of Public Health, University of São Paulo, São Paulo, Brazil.

${ }^{5}$ Department of Biostatistics, Biosciences Institute, Botucatu, São Paulo, Brazil.
} 
In recent years, the definitions commonly used in metabolic syndrome diagnosis have been shown to be not appropriate for Japanese and Asian populations. In recognizing genetic differences in the risk factors for developing metabolic syndrome-related diseases between diverse ethnicities, the American Heart Association/National Heart, Lung, and Blood Institute (AHA/NHLBI), revising the National Cholesterol Evaluation Program for Adult Treatment Panel III (NCEP ATP III), ${ }^{2}$ and the International Diabetes Federation $(\mathrm{IDF})^{8}$ established the same waist circumference cutoff values as proposed by the IDI for Japanese and other Asians to be used as criteria for defining metabolic syndrome in these populations.

There is a significant Japanese population in Brazil. The study of metabolic syndrome prevalence according to different diagnosis criteria is particularly interesting in JapaneseBrazilians because they represent a combination of genetic backgrounds for developing metabolic syndrome and "westernization" of lifestyle. In fact, previous studies have shown a high prevalence of both glucose metabolism disturbances ${ }^{9}$ and metabolic syndrome $\mathrm{e}^{10}$ in this population. However, a prior study on metabolic syndrome prevalence in JapaneseBrazilians used metabolic syndrome definitions from both the 1998 WHO criteria and a modified set of 2001 NCEP criteria. ${ }^{10}$ The WHO criteria, besides requiring evidence of insulin resistance for metabolic syndrome diagnosis, also included microalbuminuria evaluation and different cutoff values for metabolic syndrome components. ${ }^{11}$ Because measures of insulin resistance and microalbuminuria are laborious, these criteria have not been used in more recent metabolic syndrome definitions. In the modified 2001 NCEP definition, investigators used waist circumference values for Japanese; however, glucose cutoff values were $\geq 110 \mathrm{mg} / \mathrm{dL}$ and hypertension and dyslipidemia drug treatments were not taken into account. In this study, we compare the prevalence of metabolic syndrome in a Japanese-Brazilian population using definitions recently proposed by $\mathrm{IDF}^{8}$ for Japanese (IDF) and NCEP ATP III ${ }^{12}$ revised by the AHA/NHLBI ${ }^{2}$ for Westerners (NCEPwe), and Asians (NCEPas).

\section{Methods}

\section{Subjects}

This study included 650 Japanese-Brazilians, 292 men (44.9\%) and 358 women (55.1\%), aged between 30 and 88 years $(60.3 \pm 12.5)$, all residing in the city of Bauru, São Paulo State, Brazil. The participants were invited by mail, announcements on television, and in newspapers. The protocol was approved by the Research Ethics Committee of São Paulo Federal University Clinical Hospital, and all subjects provided written informed consent at the time of their initial visit to the Health Education Clinic of Sacred Heart University, Bauru, São Paulo State.

\section{Data collection}

All data were collected between November, 2005, and February, 2006. The subjects participated in a medical interview and clinical examination. BMI was calculated as weight in kilograms divided by the square of height in meters $(\mathrm{kg} /$ $\mathrm{m}^{2}$ ). Waist circumference measurements were taken using a point equidistant between the lower border of the last rib and the iliac crest. Arterial blood pressure readings were measured with an automatic Omron automatic apparatus (HEM-712C, Omron Health Care Inc., Vernon Hills, IL). Venous blood was obtained after an overnight fast of at least $10 \mathrm{~h}$. Glycemia and lipid fractions were measured using an automation kit system and apparatus from BoehringerMannheim $^{\circledR}$ (Germany). Results of BMI classification and risk for developing co-morbidities are presented and discussed based on the IDI criteria for Asian populations. ${ }^{7}$

\section{Definitions of metabolic syndrome}

Subjects were considered to have metabolic syndrome according to NCEPwe and NCEPas when 3 or more of the following criteria were present ${ }^{2}$ : fasting glycemia $\geq 100 \mathrm{mg} /$ $\mathrm{dL}$ or under drug treatment for diabetes mellitus; systolic arterial blood pressure (SBP) $\geq 130 \mathrm{mmHg}$ and/or diastolic arterial blood pressure $(\mathrm{DBP}) \geq 85 \mathrm{mmHg}$ or under drug treatment for arterial hypertension; triglycerides (TG) $\geq 150$ $\mathrm{mg} / \mathrm{dL}$ or receiving drug treatment for dyslipidemia; highdensity lipoprotein cholesterol (HDL-C) $<40 \mathrm{mg} / \mathrm{dL}$ in men and $<50 \mathrm{mg} / \mathrm{dL}$ in women or under drug treatment for dyslipidemia; waist circumference $\geq 102 \mathrm{~cm}$ in men and $\geq 88 \mathrm{~cm}$ in women for NCEPwe, and waist circumference $\geq 90 \mathrm{~cm}$ in men and $\geq 80 \mathrm{~cm}$ in women for NCEPas. The IDF definition of metabolic syndrome for Japanese subjects differs from NCEPas only for the requirement for waist circumference to be increased, in addition to the presence of at least 2 of the other criteria. ${ }^{8}$

\section{Statistical analysis}

Age, weight, height, BMI, and separated components of metabolic syndrome are expressed as mean and standard deviation (SD). Metabolic syndrome prevalence is presented in descriptive form. The nonpaired Student $t$-test was used for comparisons of age and BMI between genders. The prevalence of metabolic syndrome components according to gender and waist circumference was analyzed by the Goodman test for contrasts between and within multinomial populations. ${ }^{13}$ All data were evaluated at a $P$ level of $5 \%$.

\section{Results}

There was no difference between ages for men and women (60.6 \pm 13.3 and $60.0 \pm 11.9$ years, respectively). For the 650 study participants, mean body weight was $61.4 \pm 12.4$ $\mathrm{kg}$, height was $157 \pm 9 \mathrm{~cm}$, BMI $24.6 \pm 3.9 \mathrm{~kg} / \mathrm{m}^{2}$, and waist circumference $88 \pm 10.4 \mathrm{~cm}(92.0 \pm 9.9$ for men and $84.8 \pm 9.6$ for women). SBP and DBP were $138.2 \pm 21.8$ and $81.0 \pm 12.0$ $\mathrm{mmHg}$, respectively. Mean values for serum fasting blood glucose, TGs, and HDL-C were $111.5 \pm 31.9 \mathrm{mg} / \mathrm{dL}, 162.3 \pm$ $136.2 \mathrm{mg} / \mathrm{dL}$, and $53.6 \pm 13.1 \mathrm{mg} / \mathrm{dL}$ (49.7 \pm 12.7 for men and $56.8 \pm 12.6$ for women), respectively. According to NCEPwe, NCEPas, and IDF definitions, the prevalence of metabolic syndrome was, respectively, $46.5 \%$ (men $47.3 \%$ and women $45.8 \%$ ), $56.5 \%$ (men $60.6 \%$ and women $53.1 \%$ ), and $48.3 \%$ (men $48.6 \%$ and women $48.0 \%$ ). The Venn diagram in Fig. 1 shows that for the 650 Japanese-Brazilians examined, 38.3\% had metabolic syndrome according to all 3 definitions, whereas $43.5 \%$ did not have metabolic syndrome by all definitions, comprising a concordance of $81.8 \%$ among the 3 definitions. The frequency of subjects without metabolic syndrome 


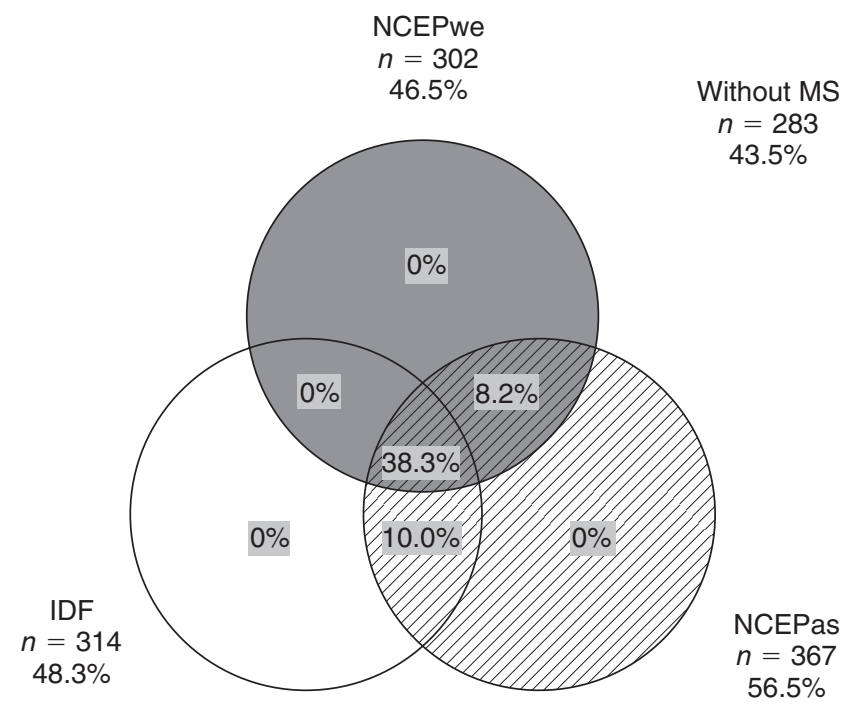

FIG. 1. Venn diagram displaying the presence or absence of metabolic syndrome (MS) using the definitions of the National Cholesterol Evaluation Program for Adult Treatment Panel III for Westerners (NCEPwe), for Asians (NCEPas), and the International Diabetes Federation (IDF).

according to IDF criteria, but with metabolic syndrome by NCEPwe and NCEPas, was $8.2 \%$; metabolic syndrome prevalence by IDF and NCEPas, but without metabolics syndrome by NCEPwe, was $10.0 \%$.

Table 1 shows the prevalence of obesity (degrees I or II) in individuals with and without metabolic syndrome according to the different metabolic syndrome definitions. Subjects with metabolic syndrome according to all 3 definitions had a significantly higher $(76.7 \%)$ prevalence of obesity, followed by individuals with metabolic syndrome by IDF and NCEPas, but not according to NCEPwe (47.7\%). The lowest obesity prevalences were found in subjects with metabolic syndrome by NCEPas and NCEPwe, but not by IDF $(7.55 \%)$, and in individuals without metabolic syndrome by all 3 definitions (18.4\%).

In our population, the prevalence of altered metabolic syndrome components was as follows: Waist circumference for Asians, 63.8\%; waist circumference for Westerners, 25.7\%; arterial pressure, 69.7\%; glycemia, 61.5\%; HDL-C, 34.6\%; and triglycerides levels, $44.5 \%$. The prevalence of altered metabolic syndrome components was substantially higher in individuals with waist circumferences above the recommended cutoff values for Asians than for those with normal circumferences, except for fasting blood glucose in male individuals (Table 2).

Table 3 shows the prevalence of altered metabolic syndrome components according to the distribution of different waist circumference values stratified by gender. Altered fasting blood glucose or drug treatment prevalence was lower in women than in men at all similar waist circumferences, except for $<80 \mathrm{~cm}$. The prevalence of alteration in other metabolic syndrome risk factors was similar between men and women at the different waist circumferences, except for HDL, which was statistically higher in women at $\geq 85$ - and $<90$-cm waist circumferences.

\section{Discussion}

In this study we evaluated the prevalence of metabolic syndrome according to 3 different definitions in a population of Japanese-Brazilians living in a Brazilian city. Although there are several definitions of metabolic syndrome, we compared 3 widely used ones. These 3 are based on relatively similar components with differences in either cutoff values for waist circumference (NCEPwe $\neq$ NCEPas $=$ IDF) or the requirement for abdominal obesity as 1 criterion (IDF). The main finding of this study is that, independent of the metabolic syndrome definition used, Japanese-Brazilians present an elevated metabolic syndrome prevalence (NCEPwe, $46.5 \%$; NCEPas, 56.5\%; and IDF, 48.3\%).

The greatest metabolic syndrome prevalence was observed using NCEPas criteria, because it possesses lower cutoff values for waist circumference, similar to IDF. In contrast to IDF, however, NCEPas does not require the abdominal obesity component. Although in the NCEPwe definition the cutoff values for waist circumference are higher, metabolic syndrome prevalence was similar between IDF and NCEPwe definitions because NCEPwe does not require abdominal obesity to be present. The higher prevalence of metabolic syndrome by NCEPas than by IDF emphasizes that other components of metabolic syndrome may be present in the absence of abdominal obesity. It is important to point out that we measured waist circumference at the point midway between the inferior margin of the ribs and the superior border of the iliac crest, as recommended by IDF. ${ }^{8}$

Table 1. Prevalence of Obesity (BMI $\geq 25.0 \mathrm{~kg} / \mathrm{m}^{2}$ ) According to the Different Definitions of Metabolic Syndrome

\begin{tabular}{lcccc}
\hline & IDF (+) & IDF (+) & IDF (-) & IDF (-) \\
& NCEPas (+) & NCEPas (+) & NCEPas (+) & NCEPas (-) \\
& NCEPwe (+) & NCEPwe (-) & NCEPwe (+) & NCEPwe (-) \\
\hline Subjects $(n)$ & 249 & 65 & 53 & 283 \\
Obesity prevalence (\%) & 76.7 & $47.7^{\mathrm{a}}$ & $7.55^{\mathrm{a}, \mathrm{b}}$ & $18.4^{\mathrm{a}, \mathrm{b}}$ \\
\hline
\end{tabular}

Goodman test.

a $P<0.01$ vs IDF $(+)$, NCEPas $(+)$, and NCEPwe $(+)$.

bP $<0.01$ vs IDF $(+)$, NCEPas $(+)$, and NCEPwe $(-)$

Abbreviations: BMI, body mass index; IDF, International Diabetes Federation; NCEPas, National Cholesterol Evaluation Program definition for Asians; NCEPwe, National Cholesterol Evaluation Program definition for Westerners. 
Table 2. Prevalence of Alteration in the Metabolic Syndrome Components in the Presence and Absence of Central Adiposity

\begin{tabular}{|c|c|c|c|c|}
\hline & \multicolumn{2}{|c|}{ Men } & \multicolumn{2}{|c|}{ Women } \\
\hline & \multicolumn{2}{|c|}{ Waist circumference (cm) } & \multicolumn{2}{|c|}{ Waist circumference $(\mathrm{cm})$} \\
\hline & $<90$ & $\geq 90$ & $<80$ & $\geq 80$ \\
\hline Number (\%) & $124(42.5 \%)$ & $168(57.5 \%)$ & $111(31.0 \%)$ & $247(69.0 \%)$ \\
\hline Age (years, mean $\pm S D$ ) & $62.7 \pm 13.6$ & $59.0 \pm 12.9^{a}$ & $56.8 \pm 12.8$ & $61.5 \pm 11.2^{\mathrm{a}}$ \\
\hline $\mathrm{BMI}\left(\mathrm{kg} / \mathrm{m}^{2}\right.$, mean $\left.\pm \mathrm{SD}\right)$ & $22.3 \pm 2.2$ & $27.6 \pm 3.2^{\mathrm{a}}$ & $20.6 \pm 1.9$ & $25.6 \pm 3.4^{\mathrm{a}}$ \\
\hline Arterial hypertension or DT (\%) & 68.5 & $79.8^{\mathrm{a}}$ & $45.0^{\mathrm{b}}$ & $74.5^{\mathrm{a}}$ \\
\hline FBG $\geq 100 \mathrm{mg} / \mathrm{dL}$ or DT $(\%)$ & 68.5 & 78.0 & $42.3^{\mathrm{b}}$ & $55.5^{\mathrm{a}, \mathrm{c}}$ \\
\hline $\begin{array}{l}\text { HDL-C }(\text { men }<40 \text { and women } \\
<50 \mathrm{mg} / \mathrm{dL}) \text { or DT }(\%)\end{array}$ & 24.2 & $40.5^{\mathrm{a}}$ & 25.2 & $40.1^{\mathrm{a}}$ \\
\hline TG ( $\geq 150$ mg/dL) or DT (\%) & 38.7 & $61.9^{\mathrm{a}}$ & $22.5^{\mathrm{b}}$ & $45.3^{\mathrm{a}, \mathrm{c}}$ \\
\hline
\end{tabular}

Arterial hypertension, systolic blood pressure $\geq 130 \mathrm{mmHg}$ or diastolic blood pressure $\geq 85 \mathrm{mmHg}$.

Goodman test for statistical analysis of the other variables. Student $t$-test for age and BMI comparisons.

a $P<0.05$ vs. normal waist circumference.

${ }^{\mathrm{b}} P<0.05$ vs. men with normal waist circumference $(<90 \mathrm{~cm})$.

'Versus men with increased waist circumference $(\geq 90 \mathrm{~cm})$.

Abbreviations: SD, standard deviation; BMI, body mass index; DT, drug treatment for the respective condition; FBG, fasting blood glucose; HDL-C, high-density lipoprotein cholesterol; TG, triglycerides.

However, according to the revised NCEP ATP III, ${ }^{2}$ waist circumference should be measured at the top of iliac crest. Therefore, it is possible that metabolic syndrome prevalence using NCEPwe and NCEPas could in fact be higher.

The prevalence of metabolic syndrome in JapaneseBrazilians is considerably higher than reported in the literature. In a recently published study in Japan, the metabolic syndrome prevalence using NCEPas and IDF for Japanese subjects was, respectively, $18.9 \%$ in men and $12.9 \%$ in women, and $11.4 \%$ in men and $11.6 \%$ in women, respectively. ${ }^{14}$ The prevalence of metabolic syndrome in Japanese-Americans and Japanese living in Japan was evaluated by Yoneda et al. ${ }^{15}$ With the revised NCEP III criteria for Wersterners, ${ }^{2}$ metabolic syndrome prevalence in Japanese-Americans was 30.9\% in men and $27.7 \%$ in women whereas in Japanese it was $13.4 \%$ in men and $14.4 \%$ in women. ${ }^{15}$ The increased prevalence of metabolic syndrome seen in Japanese subjects living outside Japan probably illustrates the importance of lifestyle and its influence on metabolic syndrome development. Obesity, a key etiological factor for metabolic syndrome development, is directly influenced by nutritional habits. ${ }^{16}$ As shown by Freire et al. ${ }^{17}$ and Sartorelli et al., ${ }^{18}$ the current dietary pattern of Japanese-Brazilians contrasts with the traditional Japanese diet, particularly concerning the higher proportion of fat and refined grains intake and very high consumption of fruits and fruit juices.

Table 3. Prevalence of altered Metabolic Syndrome Components Stratified by Gender According to Different Waist Circumference Strata

\begin{tabular}{lccccc}
\hline & & \multicolumn{4}{c}{ Waist circumference (cm) } \\
\cline { 3 - 6 } & & $<80$ & $\geq 80$ and $<85$ & $\geq 85$ and $<90$ & $\geq 90$ \\
\hline Number of subjects (\%) & M & $28(9.6 \%)$ & $32(11.0 \%)$ & $64(21.9 \%)$ & $168(57.5 \%)$ \\
& F & $111(31.0 \%)$ & $75(20.9 \%)$ & $66(19.4 \%)$ & $106(29.6 \%)$ \\
Age (years, mean \pm SD) & M & $66 \pm 14$ & $61 \pm 15$ & $62 \pm 13$ & $59 \pm 13$ \\
& F & $57 \pm 13^{\mathrm{a}}$ & $59 \pm 11$ & $60 \pm 11$ & $64 \pm 11^{\mathrm{a}}$ \\
Arterial hypertension or DT (\%) & $\mathrm{M}$ & 60.7 & 62.5 & 75.0 & 79.8 \\
& $\mathrm{~F}$ & 45.0 & 66.7 & 74.2 & 80.2 \\
FBG $\geq 100 \mathrm{mg} / \mathrm{dL}$ or DT (\%) & $\mathrm{M}$ & 57.1 & 65.6 & 75.0 & 78.0 \\
& $\mathrm{~F}$ & 42.3 & $44.0^{\mathrm{a}}$ & $57.6^{\mathrm{a}}$ & $62.3^{\mathrm{a}}$ \\
HDL-C (men $<40$ and women & $\mathrm{M}$ & 17.9 & 28.1 & 25.0 & 40.5 \\
$<50 \mathrm{mg} / \mathrm{dL})$ or DT $(\%)$ & $\mathrm{F}$ & 25.2 & 38.7 & $45.5^{\mathrm{a}}$ & 37.7 \\
TG $(\geq 150 \mathrm{mg} / \mathrm{dL})$ or DT (\%) & $\mathrm{M}$ & 21.4 & 43.8 & 43.8 & 61.9 \\
& $\mathrm{~F}$ & 22.5 & 40.0 & 43.9 & 50.0 \\
\hline
\end{tabular}

Arterial hypertension, systolic blood pressure $\geq 130 \mathrm{mmHg}$ or diastolic blood pressure $\geq 85 \mathrm{mmHg}$.

a $P<0.05$ vs male; Student $t$-test for age comparison; Goodman test for statistical analysis of the other variables.

Abbreviations: SD, standard deviation; DT, drug treatment for the respective condition; FBG, fasting blood glucose; HDL-C, high-density lipoprotein cholesterol; TG, triglycerides; M, male; F, female. 
Although interesting, the comparison between metabolic syndrome prevalence in Japanese-Brazilians and the native population is difficult because there are only a few studies, some with small sample sizes ${ }^{19}$ and others with different criteria for defining metabolic syndrome. ${ }^{20}$ Using IDF criteria for a South American population, which have the same waist circumference cutoff values as Asians, a metabolic syndrome prevalence of $17.9 \%$ was found in 140 health subjects. ${ }^{19}$ With NCEP ATP III using waist circumference cutoff values for Westerners, a metabolic syndrome prevalence of $25.4 \%$ was observed in 1,507 individuals from an urban Brazilian population. ${ }^{20}$ These prevalences are lower than in our study on Japanese-Brazilians, suggesting genetic factors influence the high metabolic syndrome prevalence of Japanese-Brazilians.

Increases in BMI are also considered measures of risk for co-morbidities. ${ }^{21}$ Using the BMI classification for Asians, we analyzed the prevalence of obesity I and II according to the different metabolic syndrome definitions. There was a high prevalence of obesity in those consistently diagnosed with metabolic syndrome by all 3 definitions (76.7\%). In those concordant with metabolic syndrome definitions for Asians (NCEPas and IDF), but not for Westerners (NCEPwe), the obesity prevalence was also elevated (47.7\%). Obviously, subjects without metabolic syndrome according to the IDF criteria, but with metabolic syndrome by the NCEPas and NCEPwe criteria, presented the lowest obesity prevalence $(7.55 \%)$, because they did not have increased waist circumference. Because obesity is a fundamental factor for developing metabolic syndrome, these findings suggest that the NCEPwe criteria should not be applied to Japanese-Brazilians. The 2000 National Nutrition Survey in Japan showed an overweight prevalence (BMI, $25.0-29.9 \mathrm{~kg} / \mathrm{m}^{2}$ ) of $24.5 \%$ for men and $17.8 \%$ for women and an obesity prevalence (BMI, $\geq 30.0$ $\mathrm{kg} / \mathrm{m}^{2}$ ) of $2.3 \%$ for men and $3.4 \%$ for women. ${ }^{22}$ If the BMI definition for Asians was taken into account, where those with BMI greater than $25.0 \mathrm{~kg} / \mathrm{m}^{2}$ are considered obese, the same National Nutrition Survey ${ }^{22}$ would have shown an obesity prevalence of $26.8 \%$ in men and $21.2 \%$ in women. Obesity prevalence in our study was $51.7 \%$ for men and $35.5 \%$ for women (data not shown), which is much higher than in Japanese living in Japan.

As well as BMI, fat distribution also influences the risk of developing co-morbidities and cardiovascular morbimortality. ${ }^{21,23}$ In this study, the prevalence of elevated abdominal fat $(63.8 \%)$ was high. If cutoff values for Westerners had been used, the elevated abdominal fat would have been $25.7 \%$, which is still higher than the abdominal obesity prevalence seen in Japanese living in Japan (7.4\%). ${ }^{24}$ We showed that abdominal obesity contributed to metabolic abnormalities as the prevalence of altered metabolic syndrome components was substantially higher in individuals with waist circumferences above the recommended cutoff values than for those with normal circumferences. The waist circumference cutoff value as a criteria for metabolic syndrome in Japanese is still a matter of controversy. ${ }^{25}$ Our data suggest that the $<90-\mathrm{cm}$ cutoff value for men may be high, because we observed a significantly greater prevalence of altered metabolic syndrome components in men than women at normal waist circumference values $(<90 \mathrm{~cm}$ for men and $<80 \mathrm{~cm}$ for women). However, when evaluating the prevalence of altered metabolic syndrome components at similar waist circumferences, we observed that men presented a higher prevalence of altered fast blood glucose or drug treatment than women at all the waist circumference strata except for $<80 \mathrm{~cm}$.

The prevalence of altered metabolic syndrome components was high in this study. Reinforcing the environmental influence on the metabolic syndrome pathophysiology, Japanese subjects residing in Japan aged between 30 and 80 years (men $52.3 \pm 9.0$ and women $53.5 \pm 9.0$ years old) presented a considerably lower prevalence of altered metabolic syndrome components. Fasting glycemia $\geq 110 \mathrm{mg} / \mathrm{dL}$ was found in $24.8 \%$ of men and $10.9 \%$ of women, low HDL in $6.6 \%$ of men and $9.2 \%$ of women, high TGs in $30.4 \%$ of men and $9.9 \%$ of women, and high blood pressure in $43.9 \%$ of men and $34.5 \%$ of women. ${ }^{26}$ It was alarming to observe that mean fasting glycemia values in our population were higher than the cutoff value of $100 \mathrm{mg} / \mathrm{dL}$ for both genders. It was also disconcerting to see that the number of individuals with elevated systemic blood pressure was higher than over 10 years before in first- and second-generation Japanese-Brazilians (first generation, $24.7 \%$ in men and $30.7 \%$ in women, and second generation, $28.7 \%$ in men and $30.9 \%$ in women). ${ }^{27}$ Furthermore, Japanese-Brazilians present a higher prevalence of systemic arterial hypertension than the general Brazilian population. ${ }^{28}$

In summary, in this study we used 3 different definitions to evaluate metabolic syndrome prevalence in Japanese-Brazilians living in a city of São Paulo State, Brazil. Independent of which definition was used, we found an elevated prevalence of metabolic syndrome in this population. Metabolic syndrome prevalence was highest when using the Asian NCEP criteria, followed by the Japanese IDF definition, with the Westerner NCEP criteria having the lowest prevalence. Additional studies are necessary to characterize the best definition of metabolic syndrome for Japanese subjects living outside Japan and exposed to different lifestyles.

\section{Acknowledgments}

We thank the Japanese-Brazilian Diabetes Study Group for their support. We also thank BioMed Proofreading and Colin Edward Knaggs for English editing. N.P.X. received a Masters fellowship from Capes, Brazil; M.P.O. and K.O. received grants from $\mathrm{CNPq}$, Brazil.

\section{Author Disclosure Statement}

No competing financial interests exist.

\section{References}

1. Isomaa B, Almgren P, Tuomi T, Forsen B, Lahti K, Nissen M, Taskinen MR, Groop L. Cardiovascular morbidity and mortality associated with the metabolic syndrome. Diabetes Care 2001;24:683-689.

2. GrundySM,CleemanJI,DanielsSR, DonatoKA,EckelRH,Franklin BA, Gordon DJ, Krauss RM, Savage PJ, Smith SC Jr, Spertus JA, Costa F. Diagnosis and management of the metabolic syndrome: an American Heart Association/National Heart, Lung, and Blood Institute Scientific Statement. Circulation 2005;112:2735-2752.

3. Krotkiewski M, Bjorntorp P, Sjostrom L, Smith U. Impact of obesity on metabolism in men and women. Importance of regional adipose tissue distribution. J Clin Invest 1983;72:1150-1162.

4. Kobayashi H, Nakamura T, Miyaoka K, Nishida M, Funahashi T, Yamashita S, Matsuzawa Y. Visceral fat accumulation contributes to insulin resistance, small-sized low-density lipoprotein, 
and progression of coronary artery disease in middle-aged non-obese Japanese men. Ipn Circ I 2001;65:193-199.

5. Tanaka S, Horimai C, Katsukawa F. Ethnic differences in abdominal visceral fat accumulation between Japanese, African-Americans, and Caucasians: A meta-analysis. Acta Diabetol 2003;1:S302-S304.

6. Fujimoto WY, Bergstrom RW, Boyko EJ, Chen K, Kahn SE, Leonetti DL, McNeely MJ, Newell LL, Shofer JB, Wahl PW. Type 2 diabetes and the metabolic syndrome in Japanese Americans. Diabetes Res Clin Pract 2000;50:S73-S76.

7. Inoue S, Zimmet P, Caterson I, Chunming C, Ikeda Y, Khalid AK, Kim YS, Bassett J. The Asia-Pacific perspective: Redefining obesity and its treatment. Australia: Melbourne: Health Communications; 2000:55.

8. Alberti KG, Zimmet P, Shaw J. Metabolic syndrome-a new world-wide definition. A Consensus Statement from the International Diabetes Federation. Diabet Med 2006;23:469-480.

9. Ferreira SR, Iunes M, Franco LJ, Iochida LC, Hirai A, Vivolo MA. Disturbances of glucose and lipid metabolism in first and second generation Japanese-Brazilians. Japanese-Brazilian Diabetes Study Group. Diabetes Res Clin Pract 1996;34:S59-S63.

10. Rosenbaum P, Gimeno S, Sanudo A, Franco L, Ferreira S. Analysis of criteria for metabolic syndrome in a population-based study of Japanese-Brazilians. Diabetes Obes Metab 2005;7:352-359.

11. Alberti KG, Zimmet PZ. Definition, diagnosis and classification of diabetes mellitus and its complications. Part 1: Diagnosis and classification of diabetes mellitus provisional report of a WHO consultation. Diabet Med 1998;15:539-553.

12. Third Report of the National Cholesterol Education Program (NCEP) Expert Panel on Detection, Evaluation, and Treatment of High Blood Cholesterol in Adults (Adult Treatment Panel III) final report. Circulation 2002;106:3143-3421.

13. Goodman LA. Simultaneous confidence intervals for contrasts among multinominal populations. Ann Math Stat 1964;35:716-725.

14. Oda E, Abe M, Veeraveedu PT, Watanabe K. Considerable disagreement among definitions of metabolic syndrome for Japanese. Circ J 2007;71:1239-1243.

15. Yoneda M, Yamane K, Jitsuiki K, Nakanishi S, Kamei N, Watanabe H, Kohno N. Prevalence of metabolic syndrome compared between native Japanese and Japanese-Americans. Diabetes Res Clin Pract 2008;79:518-522.

16. Roche HM, Phillips C, Gibney MJ. The metabolic syndrome: the crossroads of diet and genetics. Proc Nutr Soc 2005;64:371-377.

17. Freire RD, Cardoso MA, Gimeno SGA, Ferreira SRG, for the Japanese-Brazilian Diabetes Study Group. Dietary fat is associated with metabolic syndrome in Japanese Brazilians. Diabetes Care 2005;28:1779-1785.

18. Sartorelli DS, Freire RD, Ferreira SR, Cardoso MA. Dietary fiber and glucose tolerance in Japanese Brazilians. Diabetes Care 2005;28:2240-2242.

\section{Appendix}

Members of Japanese-Brazilian Diabetes Study Group: Helena Harima, Mário Kikuchi, and Katsumi Osiro (Department of Preventive Medicine, Federal University of São Paulo, Brazil); Laércio J. Franco (Department of Social Medicine, Faculty of Medicine of Ribeirão Preto, University of São Paulo, Brazil); Regina C.S. Moisés and Luiza Matsumura (Department of Internal Medicine, Federal University of São Paulo, Brazil); Newton de Barros Jr. (Department of Surgery,
19. Nakazone MA, Pinheiro A, Braile MC, Pinhel MA, de Sousa GF, Pinheiro S Jr, Brandao AC, Toledo JC, Braile DM, Souza DR. Prevalence of metabolic syndrome using NCEP-ATPIII and IDF definitions in Brazilian individuals. Rev Ass Med Bras 2007;53:407-413.

20. Marquezine GF, Oliveira CM, Pereira AC, Krieger JE, Mill JG. Metabolic syndrome determinants in an urban population from Brazil: Social class and gender-specific interaction. Int J Cardiol 2008;129:259-265.

21. Wang J, Thornton JC, Russell M, Burastero S, Heymsfield S, Pierson RNJ. Asians have lower body mass index (BMI) but higher percent body fat than do whites: Comparisons of anthropometric measurements. Am J Clin Nutr 1994;60:23-28.

22. Yoshiike N, Kaneda F, Takimoto H. Epidemiology of obesity and public health strategies for its control in Japan. $\underline{\text { Asia Pac I }}$ Clin Nutr 2002;11:S727-S731.

23. Arai H, Yamamoto A, Matsuzawa Y, Saito Y, Yamada N, Oikawa S, Mabuchi H, Teramoto T, Sasaki J, Nakaya N, Itakura H, Ishikawa Y, Ouchi Y, Horibe H, Shirahashi N, Kita T. Prevalence of metabolic syndrome in the general Japanese population in 2000. I Atheroscler Thromb 2006;13:202-208.

24. The DECODA Study Group. Prevalence of the metabolic syndrome in populations of Asian origin. Comparison of the IDF definition with the NCEP definition. Diabetes Res Clin Pract 2007;76:57-67.

25. Nishimura R, Nakagami T, Tominaga M, Yoshiike N, Tajima N. Prevalence of metabolic syndrome and optimal waist circumference cut-off values in Japan. Diabetes Res Clin Pract 2007;78:77-84.

26. Hara K, Matsushita Y, Horikoshi M, Yoshiike N, Yokoyama T, Tanaka $\mathrm{H}$, Kadowaki T. A proposal for the cutoff point of waist circumference for the diagnosis of metabolic syndrome in the Japanese population. Diabetes Care 2006;29:1123-1124.

27. Franco LJ. Diabetes in Japanese-Brazilians-influence of the acculturation process. Diabetes Res Clin Pract 1996;34:S51-S57.

28. Ferreira SR, Franco LJ, Gimeno SG, Iochida LC, Iunes M. Is insulin or its precursor independently associated with hypertension? An epidemiological study in Japanese-Brazilians. Hypertension 1997;30:641-645.

\section{Address correspondence to: Katashi Okoshi, M.D. \\ Departamento de Clinica Medica Faculdade de Medicina de Botucatu, UNESP Rubiao Junior, $S / N$ Botucatu, São Paulo 18618-000} Brazil

E-mail: katashi@fmb.unesp.br

Federal University of São Paulo, Brazil); Vania D'Almeida (Pediatrics Department, Federal University of São Paulo, Brazil); Nilce Tomita (Dental School of Bauru, University of São Paulo, Brazil); Katsunori Wakisaka (Japanese-Brazilians Study Center, Brazil); Marly Augusto Cardoso (Department of Nutrition, School of Public Health, University of São Paulo, Brazil); Daniela S Sartorelli (Faculty of Medicine of Ribeirão Preto, University of São Paulo, Brazil); and Regina C.S. Moises (Department of Endocrinology, Federal University of São Paulo, Brazil). 
This article has been cited by:

1. Maria C Foss-Freitas, Patricia M Gomes, Regina CG Andrade, Roberta C Figueiredo, Ana E Pace, Amaury L Dal Fabbro, Luciana Z Monteiro, Laercio J Franco, Milton C Foss. 2013. Prevalence of the metabolic syndrome using two proposed definitions in a Japanese-Brazilians community. Diabetology \& Metabolic Syndrome 4:1, 38. [CrossRef] 